\title{
Bioética: o novo caminho da ética em saúde
}

\author{
Bioethics: health ethics new way
}

Daniel Romero Muñoz ${ }^{(1)}$, Daniele Muñoz ${ }^{(2)}$

\begin{abstract}
Muñoz DR, Muñoz D. Bioética: o novo caminho da ética em saúde. Saúde, Ética \& Justiça. 2003;8(1/2):1-6.
RESUMO: Os autores fazem uma síntese desta nova disciplina, a bioética, mostrando suas origens, as transformações ocorridas no cenário social, político e tecnológico que a precederam, os fatos e instituições que contribuíram para sua consolidação, as primeiras publicações e sua institucionalização. Citam os fatores que, segundo Rothman, foram decisivos para o declínio da ética hipocrática que acompanhou a ascensão da bioética.
\end{abstract}

DESCRITORES: Bioética/história. Ética médica.

\section{INTRODUÇÃO}

A bioética é uma disciplina nova que vem tendo cada vez mais destaque na área de saúde, ganhando cada vez mais terreno na própria medicina em detrimento da tradicional ética hipocrática.

Esta denominação, bioética, é atribuída ao oncologista norte-americano Van Rensselaer Potter, da Universidade de Wisconsin, que a utilizou pela primeira vez no livro Bioethics: bridge to de future'. Seu objetivo era promover um novo diálogo entre ciência e humanismo que pareciam incapazes de comunicar-se, por isso ele apontou a bioética como uma ponte para uma futura ligação entre esses saberes que até então trilhavam caminhos paralelos ${ }^{2}$.

Potter $^{1}$, preocupado com a sobrevivência ecológica do planeta e com a democratização do conhecimento científico, aspirava produzir uma disciplina que combinasse o conhecimento biológico (bio) com o conhecimento do sistema de valores

\footnotetext{
(1) Professor responsável pela disciplina de Medicina Legal da Faculdade de Medicina da Universidade de São Paulo e de Bioética da Faculdade de Ciências Médicas da Santa Casa de São Paulo.

(2) Acadêmica de medicina da Faculdade de Medicina da Universidade de Mogi das Cruzes, São Paulo.

Endereço para correspondência: Daniel Romero Muñoz. Rua Teodoro Sampaio, 115, CEP: 05405-000 Cerqueira César, São Paulo, SP. E-mail: danielmunoz@bol.com.br
} 
humanos (ética) ${ }^{3}$. Sua intenção era criar uma nova matriz cultural, um modelo de pensamento integrador'.

O importante da proposta futurista de Potter é a idéia de que a constituição de uma ética aplicada às situações de vida seria o caminho para a sobrevivência da espécie humana. E, mais curioso ainda: para essa ciência da sobrevivência não seria preciso um conhecimento rigoroso da técnica, mas sim respeito aos valores humanos ${ }^{3}$.

Esta proposição de Potter ${ }^{1}$ de associar a biologia (entendida, em sentido amplo, como o bem-estar dos seres humanos, dos animais e do meio ambiente) e a ética é o que hoje se mantém como o espírito da bioética ${ }^{3}$. O termo bioética enfatiza os dois ingredientes mais importantes para alcançar a prudência que ele julgava necessária: o conhecimento biológico associado aos valores humanos'.

\section{Antecedentes da bioética}

O nascimento da bioética foi precedido de importantes transformações ocorridas no cenário social, político e tecnológico entre os anos 1960 e 1970.

Por um lado, um grande desenvolvimento tecnológico fez surgir dilemas morais inesperados relacionados à prática biomédica. Por outro, os anos 1960 foram também a era da conquista dos direitos civis, o que fortaleceu o ressurgimento de movimentos sociais organizados, como o feminismo, o movimento hippie e o movimento negro, entre outros grupos de minorias sociais, promovendo, com isso, um revigoramento dos debates acerca da ética normativa e aplicada. Esses diferentes movimentos sociais adotaram como bandeira e trouxeram à tona questões relacionadas à diversidade de opiniões, ao respeito pela diferença e ao pluralismo moral ${ }^{3}$.

Não se pode deixar de mencionar a mudança no espírito geral da época. Uma situação classificada então como "fuga da autoridade", quando não sua completa rejeição, impregnou toda a década de 60. Algumas de suas manifestações foram tão inofensivas como adesivos para automóveis dizendo "Abaixo a autoridade", enquanto outras, mais violentas, incluíram os movimentos estudantis da França, da Europa em geral e de muitos outros países ${ }^{4}$.
No entanto, paralelamente ao processo de crítica moral desencadeada pelos grupos sociais, houve importantes transformações em instituições tradicionais, como os padrões de família, as crenças religiosas e até mesmo a socialização formal das crianças por meio das escolas.

O filósofo Albert Jonsen pontua três acontecimentos que exerceram um papel particularmente importante na consolidação da disciplina ${ }^{5}$.

O primeiro foi um artigo da jornalista Shana Alexander intitulado "Eles decidem quem vive, quem morre", publicado na revista Life, em 1962, que contava a história e os desdobramentos da criação de um comitê de ética hospitalar em Washington (Comitê de Admissão e Políticas do Centro Renal de Seattle). O Comitê de Seattle, como ficou conhecido, tinha o objetivo de definir prioridades para a alocação de recursos em saúde. Uma de suas primeiras medidas foi a seleção, dentre pacientes renais crônicos, daqueles que poderiam fazer parte do programa de hemodiálise recém-inaugurado na cidade. Como havia um número de pacientes superior à disponibilidade de máquinas, os médicos optaram por delegar os critérios de seleção de atendimento para um pequeno grupo de pessoas, todos leigos em medicina. Cabia a esse grupo eleger critérios não-médicos de seleção para o tratamento. De uma forma inusitada, então, o processo de decisão médica passou para o domínio público. Para Jonsen, esse, mais que qualquer outro evento, assinalou a ruptura entre a bioética e a tradicional ética médica, supostamente um conhecimento de domínio exclusivo do profissional de saúde e, mais especificamente, do médico ${ }^{3}$.

O segundo evento ocorreu em 1966, quando Henry Beecher, professor de anestesiologia de Harvard, publicou, no New England Journal of Medicine, seu artigo "Ética e investigação clínica". Ele colecionou relatos de pesquisas científicas em seres humanos, publicadas em periódicos de grande prestígio internacional (New England Journal of Medicine, Journal of Clinical Investigation, Journal of American Medical Association, Circulation), realizadas em condições éticas pouco respeitosas. Ele mostrava que cerca de $12 \%$ dos artigos médicos publicados em 1964 em uma importante revista continham graves transgressões à ética ${ }^{3,4}$. 
Alguns exemplos perversos de pesquisas, conhecidos na literatura médica pelo ordenamento numérico original de Beecher, ficaram famosos, como o exemplo 2, que consistia na retirada intencional do tratamento à base de penicilina de operários com infecções por estreptococos, sem que eles soubessem, para permitir o estudo de meios alternativos de prever complicações. No exemplo 16, a pesquisa exigia a inoculação intencional de vírus da hepatite em indivíduos institucionalizados por retardo mental, para possibilitar o acompanhamento da etiologia da doença. No exemplo 17, os pesquisadores injetaram células cancerosas vivas em 22 pacientes idosos e senis hospitalizados, sem que eles soubessem, com o objetivo de acompanhar as respostas imunológicas do organismo ${ }^{3}$.

O terceiro evento selecionado por Jonsen é o primeiro transplante cardíaco, realizado em 1967 na Africa do Sul, pelo Dr. Christian Barnard. O nó da questão girava em torno da origem do órgão, pois a comunidade médica se perguntava como Barnard poderia garantir que o doador estava realmente morto no momento do transplante. É evidente que essa técnica salvadora de vidas (transplante), lançava perguntas de difícil resposta: - Quando alguém deve ser considerado morto? A morte é um processo, no qual se podem descrever etapas? Há um momento em que esse processo pode ser considerado irreversível? Esse momento deve ser determinado pela ciência, pela prática ou pela lei? A vida consciente é a única forma de vida? Se o cérebro morre, morre também a pessoa? ${ }^{3}$.

Além dos eventos citados por Jonsen, outros são lembrados como de importância fundamental na história da bioética, como por exemplo, a luta pelos direitos dos pacientes nos Estados Unidos.

\section{Consolidação da bioética}

Vários fatos e instituições são citados como de fundamental importância para a consolidação da bioética como uma nova disciplina. Enumeramos, a seguir, os que têm sido mais citados.

\section{Hasting Center}

Esta instituição foi fundado em 1969, nos Estados Unidos, com a finalidade de promover o exame da ética e dos valores em relação à medicina e os avanços científicos ${ }^{4}$.

\section{Kennedy Institute of Ethics}

Fundado em 1971 na Universidade de Georgetown, Washington, inicialmente sob a denominação de The Joseph and Rose Kennedy Institute for the Study of Human Reproduction and Bioethics, logo se transformou no Kennedy Institute of Ethics ${ }^{4}$. É considerado um pioneiro na institucionalização da bioética. Segundo Reich ${ }^{6}$, a bioética teria tido seu nascimento em dois locais: na Universidade de Wisconsin, com Potter, criador do conceito, e na Universidade de Georgetown, em Washington, com Hellegers que, diante da existência do neologismo, teria sido o primeiro a utilizá-lo institucionalmente com o intuito de designar uma nova área de atuação: a que atualmente conhecemos como bioética.

3. O caso Tuskegee e as comissões de ética em pesquisa

Tuskegee é uma cidade do Estado de Alabama, USA, na qual se iniciou em 1932 um estudo sobre a "história natural" da sífilis não tratada. Os "voluntários", todos negros, jamais foram informados sobre o objetivo das observações, tampouco sobre os riscos que corriam. Em troca da participação, receberam transporte, alimentação e funeral gratuitos. Embora a penicilina estivesse disponível desde 1946, eles nunca foram tratados e o caso veio a público, em 1972, porque um funcionário do Serviço de Saúde Pública comentou à imprensa achar estranha essa ausência de intervenção na enfermidade. O caso influiu na decisão do Congresso dos Estados Unidos de criar, em 1974, uma Comissão Nacional para a Proteção dos Sujeitos Humanos de Pesquisa Biomédica e Comportamental, que foi logo seguida pela Comissão Presidencial para o Estudo dos Problemas Éticos em Medicina e na Investigação Biomédica e Comportamental, em 1979.

\section{O Relatório Belmont}

Em 1978, após quatro anos de trabalho, a Comissão Nacional para a Proteção dos Sujeitos Humanos de Pesquisa Biomédica e Comportamental apresentou o resultado de seu trabalho, que ficou conhecido como Relatório Belmont (nome de seu presidente). A proposta da Comissão foi articular três princípios éticos, supostamente universais, que promoveriam as bases conceituais para a formulação, a crítica e a interpretação de dilemas morais envolvendo a pesquisa científica ${ }^{3}$. Foram escolhidos os seguintes princípios: 
$1^{\circ}$ ) respeito pela pessoas

Este princípio carrega consigo dois outros pressupostos éticos:

- os indivíduos devem ser tratados como agentes autônomos;

- as pessoas com autonomia diminuída (os socialmente vulneráveis) devem ser protegidas de qualquer forma de abuso.

Do ponto de vista prático, isto significa que a vontade deve ser um pré-requisito fundamental para a participação na pesquisa científica, fazendo com que a concessão do consentimento somente tivesse validade após a informação e a compreensão sobre a totalidade da pesquisa a ser realizada ${ }^{3}$.

$2^{\circ}$ ) Beneficência

É o bonum facere (fazer o bem), que remonta à antigüidade clássica com o juramento hipocrático, o qual enfatiza a necessidade de não provocar danos, maximizar os benefícios e minimizar os riscos possíveis, buscando sempre o bem-estar dos enfermos $^{2}$. Na prática, o princípio propõe uma avaliação sistemática e contínua da relação risco/ benefício para as pessoas envolvidas ${ }^{3}$.

\section{$3^{\circ}$ ) Justiça}

Baseado na eqüidade social. As regras de justiça serviriam para contrabalançar os diferentes, e muitas vezes conflituosos, interesses que emergem da vida coletiva. A justiça distributiva traz à tona o problema da resolução de conflitos existentes entre reivindicações e interesses particulares em contraposição aos interesses da sociedade. O princípio de justiça aponta com maior ênfase para o papel das sociedades e dos movimentos sociais organizados ${ }^{3}$.

\section{Primeiras publicações}

\section{Problemas morais na medicina}

Publicado pela primeira vez em 1976, esse livro, organizado pelo filósofo Samuel Gorovitz ${ }^{5}$, foi o precursor de uma série de estudos que correlacionavam os estudos éticos às situações médicas conflituosas, tais como o aborto e a eutanásia. A iniciativa desse livro marcou a proposta interdisciplinar da bioética: médicos e filósofos foram convidados a expor suas opiniões e argumentações sobre temas clássicos de conflito moral na saúde. Na esteira do movimento crítico da época, Gorovitz ${ }^{5}$, na introdução do livro, também fazia referências à ruptura com o tradicionalismo da ética médica, isto é, com a falência da ética a beira do leito, tema retomado posteriormente por Rothman ${ }^{8}$. Segundo Gorovitz ${ }^{5}$, o postulado comumente aceito pelo senso comum de que o "especialista em decisões médicas é também especialista em decisões éticas" deveria ser questionado, tornando possível que outros atores sociais participassem do processo de decisão ética²

\section{Encyclopedia of Bioethics ${ }^{6}$}

Em 1971 Warren T. Reich convidou 285 autores para escrever o que se publicaria em 1978 como a Encyclopedia of Bioethics ${ }^{6}$. Ela define a disciplina como estudo sistemático da conduta humana no campo das ciências da vida e da atenção à saúde, examinada à luz dos princípios e valores morais ${ }^{2,4}$.

\section{Princípios da Ética Biomédica ${ }^{7}$}

A publicação desse livro, em 1979, consolidou a força teórica da bioética, principalmente nas universidades estadunidenses. Nas palavras dos autores, "este livro oferece uma análise sistemática dos princípios morais que devem ser aplicados à biomedicina ..."7.

Os autores desta obra,Tom Beauchamp, filósofo que havia participado do Relatório Belmont, em parceria com o teólogo James Childress, sugerem quatro princípios éticos como base de uma teoria bioética consistente ${ }^{7}$ :

\section{1) Autonomia}

Correspondente ao respeito pelas pessoas do relatório Belmont;

2º) Beneficência

É o princípio hipocrático de bonum facere;

3o) Não maleficência

É também um princípio hipocrático: o primum non nocere;

$4^{\circ}$ ) Justiça

Eqüidade: princípio formal de justiça no qual os iguais devem ser tratados de modo igual e os desiguais de modo desigual. $\mathrm{O}$ que está em jogo não é que todos devem receber o mesmo, mas que cada um deve receber o que the é proporcional, o 
que merece, aquilo a que tem "direito". Dizemos que um acordo é justo quando é eqüitativo e merecido".

\section{Institucionalização da bioética}

A análise genealógica feita por Jonsen sobre a trajetória e desenvolvimento da bioética alcança, nos anos de 1980 e 1990, um período mais marcadamente definido pela institucionalização da disciplina. Segundo esse autor, essa fácil e rápida difusão do tema pelo mundo é uma resposta à angústia das sociedades diante das implicações políticas e sociais decorrentes do desenvolvimento da ciência, da tecnologia e da medicina. Por ser a bioética um campo disciplinar compromissado com o conflito moral na área da saúde e da doença dos seres humanos e dos animais, seus temas dizem respeito a situações de vida que nunca deixaram de estar em pauta na história da humanidade ${ }^{3}$.

Talvez no que se refere à pesquisa biomédica, um elemento decisivo para essa mudança de mentalidade tenha sido a formação de um discurso crítico com relação à pesquisa científica, não aceitando mais a premissa de que o desenvolvimento da ciência estaria acima de qualquer suspeita para o bem-estar e a saúde da humanidade. Começaram, portanto, a surgir dúvidas, dos pontos de vista ético, jurídico, econômico e mesmo político, sobre certos avanços relacionados à experimentação humana, ao controle comportamental, à engenharia genética, à saúde reprodutiva, ao transplante de órgãos, dentre tantos outros temas atualmente analisados pela bioética ${ }^{3}$.

\section{O declínio da ética hipocrática}

Rothman ${ }^{8}$ considera que essa situação abriu espaço para que uma mudança de atitude surgisse nos campos da medicina, da relação entre médicos e pacientes e nas instituições de saúde.

A medicina teve uma abertura gradual e, de uma profissão fechada e autoritária, passou a dialogar com os que Rothman ${ }^{8}$ denominou de estrangeiros. Em seu livro, Estrangeiros à Beira do Leito: uma história de como a Bioética e o Direito transformaram a Medicina (1991), ele cita os estrangeiros que teriam contribuído para o declínio da ética médica tradicional: primeiro os filósofos, os teólogos e os advogados e, depois os sociólogos e os psicólogos, que passaram a opinar sobre a profissão médica, porém sob outras perspectivas profissionais ${ }^{3}$.

Rothman ${ }^{8}$ sugere que essa invasão da medicina pelos estrangeiros tenha ocorrido principalmente em nome da crescente especialização e despersonalização do exercício médico, um processo que ocorreu paralelamente à perda de confiança dos pacientes em seus médicos ${ }^{3}$. Esses fatores contribuíram para que a ética médica de inspiração hipocrática fosse perdendo sua força. Os avanços científicos e tecnológicos começaram a ameaçar a tranqüilidade do processo ético de tomada de decisão na prática médica. De amigos e confidentes morais - no modelo do médico de família - os médicos e pacientes tornaram-se distantes morais $^{3}$. Esse processo de estranhamento moral foi de fundamental importância para a invasão da medicina pelos estrangeiros.

Muñoz DR, Muñoz D. Bioethics: health ethics new way. Saúde, Ética \& Justiça. 2003;8(1/2):1-6.

\begin{abstract}
S: The authors make a synthesis of this new discipline, the bioethics, showing its origins, the changes carried out in the social, political and technological scenario that preceded it, the facts and institutions that have contributed to its consolidation, the first publications and the institutionalisation. They cite factors that, according to Rothman, were definitive to the decline of Hipocratic ethics which accompanied the ascension of bioethics.
\end{abstract}

KEY WORDS: Bioethics/history. Ethics, medical. 


\section{REFERÊNCIAS}

1. Potter VR. Bioethics: bridge to the future. New Jersey: Prentice-Hall, 1971.

2. Séguin E. Biodireito. Rio de Janeiro: Lumens Juris; 2001.

3. Diniz D, Guilhem D. O que é Bioética? São Paulo: Brasiliense; 2002.

4. Lolas F. Bioética-O que é? Como se faz? São Paulo: Loyola; 2001.

5. Gorovitz S, Jameton AL, Macklin D, O'Connor JM,
Perrin BPSC, Sherwin S. Moral problems in medicine. New Jersey: Prentice-Hall; 1976.

6. Reich WT, editor. Encyclopedia of bioethics. New York: Simon \& Schuster MacMillan; 1995.

7. Beauchamp T, Childress JF. Principles of biomedical ethics. New York: Oxford University Press; 1979.

8. Rothman DJ. Strangers at the bedside: a history of how law and bioethics transformed medical decisons making. United State: Basic Books; 1991. 